\title{
Anti-Sarcocystis Antibodies in Lambs Deprived of Colostrum
}

\author{
Camila Encarnação Minuzzi ${ }^{1}$ [ $\cdot$ Fernando de Souza Rodrigues ${ }^{3} \cdot$ Camila Balconi Marques $^{1} \cdot$ Tiago Gallina $^{2}$. \\ Thiago Cardoso dos Santos ${ }^{2}$. Luiza Pires Portella ${ }^{1} \cdot$ Patricia Bräunig ${ }^{1} \cdot$ Alisson Rodrigues Döhler ${ }^{1}$. \\ Luis Antonio Sangioni ${ }^{1} \cdot$ Fernanda Silveira Flores Vogel ${ }^{1}$
}

Received: 10 July 2019 / Accepted: 28 August 2019 / Published online: 30 September 2019

(C) Witold Stefański Institute of Parasitology, Polish Academy of Sciences 2019

\begin{abstract}
Introduction The objective of this study was to evaluate the presence of anti-Sarcocystis spp. specific IgG antibodies in serum samples from precolostral lambs to determine the occurrence of transplacental transmission of Sarcocystis spp. in sheep. Methods Blood samples were collected from 80 ewes and their respective lambs, immediately after lambing and before colostrum ingestion, respectively. The presence of anti-Sarcocystis spp. IgG was evaluated in serum samples using the indirect fluorescent antibody test (IFAT). Positive samples of the lambs were submitted to titration and IFAT to detect anti- $T$. gondii and anti-N. caninum specific IgG.

Results Anti-Sarcocystis spp. IgG was detected in $62.5 \%$ of the ewes (50/80) and in $4 \%$ of the lambs of the seropositive ewes (2/50). None of the lambs from seronegative ewes were positive. The final titers of the positive lambs were 80 . No cross reaction was detected among the positive samples to anti-Sarcocystis spp., anti-N. caninum, and anti-T. gondii IgG. The detection of anti-Sarcocystis spp. antibodies in serum samples of lambs deprived of colostrum suggests transplacental transmission of infection. Thus, the vertical transmission may be an alternative route of infection of Sarcocystis spp. also in sheep. Further studies are warranted to confirm transplacental transmission in sheep and to explain the importance of this infection pathway.
\end{abstract}

Keywords Sarcocystis $\cdot$ Precolostral serology $\cdot$ IFAT $\cdot$ Sheep $\cdot$ Transplacental transmission $\cdot$ Congenital transmission

Over a 100 species of the protozoon Sarcocystis are distributed worldwide infecting a wide range of domestic and wild animals [8]. The life cycle of this protozoan has definitive and intermediate hosts. The definitive hosts are usually the predators, such as felids, canids, and humans. Sexual reproduction occurs in the intestine of the definitive host and results in the excretion of oocysts in the feces [9].

Camila Encarnação Minuzzi

camila.minuzzi03@gmail.com

1 Laboratório de Doenças Parasitárias (Ladopar), Departamento de Medicina Veterinária Preventiva, Universidade Federal de Santa Maria (UFSM), Av. Roraima 1000, Prédio 44, Sala 5139, Santa Maria, RS 97105-900, Brazil

2 Laboratório de Parasitologia e Doenças Parasitárias, Universidade Federal do Pampa (UNIPAMPA), BR 472, SN, Uruguaiana, RS, Brazil

3 Departamento de Medicina Veterinária Preventiva, Universidade Estadual de Londrina, Rodovia Celso Garcia Cid Pr 445 km 380, Londrina, PR 86057-970, Brazil
Intermediate hosts (typically, herbivores) become infected by ingesting the water or food contaminated with oocysts excreted from the definitive host [8]. Sheep can be infected by at least four species of Sarcocystis. S. tenella and S. arietcanis form microscopic cysts (microcysts) in muscles and have canids as the definitive host. S. gigantea and $S$. medusiformis form macroscopic cysts (macrocysts) in muscles and have the domestic cat (Felis catus) as the definitive host [8]. In studies on slaughtered sheep in Rio Grande do Sul, microcysts were found in $76.2 \%$ of myocardial [22], and both macrocysts and microcysts were found in $96.1 \%$ of muscle tissue [16].

Sarcocystosis usually presents a subclinical course in small ruminants. Clinical infection can result in anemia, weight loss, and apathy. Other signs associated with the central nervous system such as ataxia, paresis, myopathy, weakness, and death have been observed [8]. Sarcocystis spp. infection may eventually cause reproductive disorders [21] and macrocysts were related to condemnation of carcasses in slaughterhouses [15]. 
Some aspects of the life cycle of Sarcocystis spp. are well known; however, some routes of infection have not been investigated in small ruminants. Transplacental transmission has already been demonstrated in other Apicomplexa protozoa, such as Neospora caninum [6] and Toxoplasma gondii [3]. In sheep, the transplacental transmission rate of N. caninum and T. gondii is 70-90 [11] and 60-70\% [24], respectively. Transplacental transmission of Sarcocystis spp. has been suggested in horse [1,8] and cattle [17] but it has not been demonstrated in sheep.

The objective of this study was to evaluate the presence of anti-Sarcocystis spp. specific IgG antibodies in serum samples from precolostral lambs to determine the occurrence of transplacental transmission of Sarcocystis spp. in sheep.

This study was conducted in a sheep farm located in the west region of Rio Grande do Sul, a subtropical area in southern Brazil. Eighty ewes of breed Corriedale, Ideal, and Merino and their lambs were used in the experiment. All ewes gave birth to healthy lambs and $36.25 \%$ and $6.25 \%$ of the ewes had twins and triplets lambs, respectively. The sheep had contact with cats and dogs, and no previous reports of abortion were related. The perinatal death rate was $3.75 \%$.

Blood samples were collected from the ewes and from their respective lambs, immediately after lambing and before colostrum ingestion, respectively. After blood collection, it was centrifuged at $250 \times \mathrm{g}$ for $12 \mathrm{~min}$ to obtain the serum. Serum samples were frozen and stored until processing and tested using the indirect fluorescent antibody test (IFAT) for anti-Sarcocystis spp. IgG. Merozoites obtained from $S$. gigantea cysts were used as antigens. The serum samples were diluted in PBS at the dilution ratio of 1:40 [19]. An anti-sheep IgG fluorescein isothiocyanate conjugate (Sigma Bio Sciences, St. Louis, USA) was used at 1:500 dilution. Positive and negative serum samples were used as controls. Presence of complete peripheral fluorescence of merozoites was considered positive [4]. Positive samples of the lambs were submitted to titration and IFAT to detect anti-T. gondii and anti-N. caninum specific IgG according to [19].

All experimental practices involving animals were approved by the Ethics Committee for Animal Experimentation at Universidade Federal de Santa Maria (UFSM) (protocol number: 9246060418).

The occurrence of vertical transmission of Sarcocystis spp. infection was investigated by detecting antibodies in ewes and their respective lambs after lambing and prior to colostrum ingestion. Anti-Sarcocystis spp. IgG was detected in $62.5 \%$ of the ewes $(50 / 80)$ and in $4 \%$ of the newborn lambs of the seropositive ewes (2/50). The final titers of the positive lambs were 80 . None of the lambs from seronegative ewes were positive. No cross reaction was detected among the positive samples to anti- Sarcocystis spp., anti- $N$. caninum, and anti-T. gondii IgG.
The detection of anti-Sarcocystis spp. antibody in serum samples from lambs deprived of colostrum suggests the exposure of the fetus to antigens of the protozoan during gestation, and therefore transplacental transmission of the infection. No studies have been conducted on the intrauterine exposure to Sarcocystis spp. in sheep. In horse studies, anti-Sarcocystis antibodies were detected in foals (7.4\%) deprived of colostrum [1]. IFAT is the most frequently used test to detect anti-protozoa IgG and is considered the gold standard for the diagnosis of these infections [7, 13].

In cattle, cross-reactivity by IFAT among $S$. cruzi, $N$. caninum, and $T$. gondii is negligible $[5,10]$. Moreover, Moré et al. [17] concluded that serology using IFAT is a suitable method to diagnose $S$. cruzi, $T$. gondii, and $N$. caninum infections in cattle because of its specificity. However, no studies have been conducted to evaluate cross-reactivity among the Apicomplexa protozoa in sheep using serological tests, and this is important because, as it was mentioned, Sarcocystis spp. in sheep are different from those in cattle [10].

The proportion of lambs in which anti-Sarcocystis spp. antibodies were detected as a result of possible endogenous transmission of infection was relatively low (4\%). The genus Sarcocystis belongs to the phylum Apicomplexa. In this phylum, there are other genera, such as $N$. caninum [6] and $T$. gondii [3], that efficiently use the endogenous transmission pathway. Therefore, the possibility of vertical transmission of infection by Sarcocystis spp. was expected.

The occurrence of anti-Sarcocystis spp. antibody in sheep has not been commonly reported [8]. In the present study, the detection rate of anti-Sarcocystis spp. antibody was $62.5 \%$ by IFAT. In Spain, the frequency of detection of anti-Sarcocystis spp. antibody in sheep using the indirect hemagglutination (IHA) technique was $88 \%$ [20]. Most studies detected microcysts in the musculature through direct examination or molecular techniques, such as polymerase chain reaction (PCR). The frequency of detection of microcysts in muscle tissue in Brazil ranges from 76.2 to $96.1 \%$ $[2,22]$ and in the world from 70 to $100 \%[12,14,18,23]$.

The Sarcocystis spp. infection has a high prevalence and large distribution because of exogenous transmission [8]. Based on the low frequency of antibody detection in precolostral lambs in this study, the endogenous transmission could be an alternative route of infection, but not the most important one. Although it has not been investigated in this study, the exogenous route seems to have greater efficiency in transmission.

The detection of anti-Sarcocystis spp. antibody in serum samples from lambs deprived of colostrum suggests the occurrence of transplacental transmission of the infection. The vertical transmission may be an alternative route of infection used by Sarcocystis spp. in sheep. Further studies with more specific serology test are necessary to confirm transplacental transmission of Sarcocystis spp in sheep. 
Acknowledgements The authors are grateful to the Coordination for the Improvement of Higher Education Personnel (CAPES), Brazil, for the financial support.

\section{Compliance with Ethical Standards}

Conflict of Interest The authors declare that they have no conflict of interest.

\section{References}

1. Antonello AM, Cadore GC et al (2016) Intra-uterine exposure of horses to Sarcocystis spp. antigens. Arq Bras Med Vet Zootec 68:271-275. https://doi.org/10.1590/1678-4162-8227

2. Bittencourt MV, Meneses IDS et al (2016) Sarcocystis spp. in sheep and goats: frequency of infection and species identification by morphological, ultrastructural, and molecular tests in Bahia, Brazil. Parasitol Res 115:1683-1689. https://doi.org/10.1007/ s00436-016-4909-5

3. Buxton D, Rodger SM (2008) Toxoplasmosis and neosporosis. In: Aitken ID (ed) Diseases of Sheep, 4th edn. Wiley-Blackwell, Hoboken, pp 112-118. https://doi.org/10.1177/104063870301500 103

4. Duarte PC, Daft BM et al (2003) Comparison of a serum indirect fluorescent antibody test with two Western blot tests for the diagnosis of equine protozoal myeloencephalitis. J Vet Diagn Invest 15:8-13. https://doi.org/10.1177/104063870301500103

5. Dubey JP, Lindsay DS et al (1996) Serologic responses of cattle and other animals infected with Neospora caninum. Am J Vet Res 57:329-336

6. Dubey JP (2003) Review of Neospora caninum and neosporosis in animals. Korean J Parasitol 41:1-16. https://doi.org/10.3347/ kjp.2003.41.1.1

7. Dubey JP, Schares G (2011) Neosporosis in animals - the last five years. Vet Parasitol 180:90-108. https://doi.org/10.1016/j.vetpa r.2011.05.031

8. Dubey JP, Calero-Bernal R et al (2016) Sarcocystosis of animals and humans, 2nd edn. CRC Press, Boca Raton, pp 1-481

9. Gjerde B (2013) Phylogenetic relationships among Sarcocystis species in cervids, cattle and sheep inferred from the mitochondrial cytochrome c oxidase subunit I gene. Int J Parasitol 43:579591. https://doi.org/10.1016/j.ijpara.2013.02.004

10. Gondim LFP, Mineo JR, Schares G (2017) Importance of serological cross-reactivity among Toxoplasma gondii, Hammondia spp., Neospora spp., Sarcocystis spp. and Besnoitia besnoiti. Parasitology 144:851-868. https://doi.org/10.1017/S00311820170000 63

11. González-Warleta M, Castro-Hermida JA, Calvo C, Pérez V, Gutiérrez-Expósito D, Regidor-Cerrillo J, Ortega Mora LM, Mezo M (2018) Endogenous transplacental transmission of Neospora caninum during successive pregnancies across three generations of naturally infected sheep. Vet Res 49(1):106

12. Hu JJ, Huang S et al (2017) Morphology, molecular characteristics, and demonstration of a definitive host for Sarcocystis rommeli from cattle (Bos taurus) in China. J Parasitol 103:471-476. https ://doi.org/10.1645/16-187

13. Langoni L, Silva AV et al (2007) Utilization of modified agglutination test and indirect immunofluorescent antibody test for the detection of Toxoplasma gondii antibodies in naturally exposed horses. Braz J Vet Res Anim Sci 44:27-32. https://doi. org/10.11606/issn.1678-4456.bjvras.2007.26657

14. Latif BMA, Al-Delemi JK et al (1999) Prevalence of Sarcocystis spp. in meat-producing animals in Iraq. Vet Parasitol 84:85-90

15. Martínez-Navalón B, Anastasio-Giner B et al (2012) Sarcocystis infection: a major cause of carcass condemnation in adult sheep in Spain. J Agric Res 10:388-392. https://doi.org/10.5424/ sjar/2012102-523-11

16. Minuzzi CE, Portella LP et al (2019) Occurrence of Sarcocystis gigantea macrocysts and high frequency of $S$ tenella microcysts in sheep from southern Brazil. Vet Parasitol Reg Stud Rep 15:100256. https://doi.org/10.1016/j.vprsr.2018.12.002

17. Moré G, Bacigalupe D, Basso W, Rambeaud M, Beltrame F, Ramirez B, Venturini MC, Venturini L (2009) Frequency of horizontal and vertical transmission for Sarcocystis cruzi and Neospora caninum in dairy cattle. Vet Parasitol 160:51-54

18. Moré G, Basso W et al (2008) Diagnosis of Sarcocystis cruzi, Neospora caninum, and Toxoplasma gondii infections in cattle. Parasitol Res 102:671-675. https://doi.org/10.1007/s0043 6-007-0810-6

19. Ortega-Mora LM, Gottstein B et al (2007) Protozoal abortion in farm ruminants: guidelines for diagnosis and control. CABI Int, Wallingford

20. Pereira A, Bermejo M (1988) Prevalence of Sarcocystis cysts in pigs and sheep in Spain. Vet Parasitol 27:353-355

21. Pescador CA, Corbellini LG et al (2007) Aborto ovino associado com infecção por Sarcocystis sp. Pesq Vet Bras 27:393-397. https ://doi.org/10.1590/S0100-736X2007001000001

22. Portella LP, Cadore GC et al (2016) Detecção molecular de protozoários da família Sarcocystidae em ovinos no Estado do Rio Grande do Sul, Brasil. Ciênc Rural 46:1613-1617. https://doi. org/10.1590/0103-8478cr20151365

23. Shekarforoush SS, Razavi SM et al (2005) Prevalence of Sarcocystis species in slaughtered goats in Shiraz, Iran. Vet Rec 156:418-420. https://doi.org/10.1136/vr.156.13.418

24. Williams RH, Morley EK et al (2005) High levels of congenital transmission of Toxoplasma gondii in longitudinal and crosssectional studies on sheep farms provides evidence of vertical transmission in ovine hosts. Parasitology 130:301-307

Publisher's Note Springer Nature remains neutral with regard to jurisdictional claims in published maps and institutional affiliations. 